\title{
A MATHEMATICAL MODEL FOR DETERMINING THE OPTIMAL SIZE OF A RESERVE RESOURCE POOL FOR ESSENTIAL SERVICES: HUMAN RESOURCES
}

\author{
S.C. Saha ${ }^{1}$, Seena.P ${ }^{2}$, Subodh Deb Barma ${ }^{3}$ \\ ${ }^{1}$ Professor, ${ }^{2}$ Assistant Professor, ${ }^{3}$ Research Scholar \\ ${ }^{1,3}$ Mechanical Engineering Department, ${ }^{2}$ Production Engineering Department \\ National Institute of Technology, Agartala-799055 \\ subashchandrasaha@yahoo.in,zeenapriyan@gmail.com,Subodh_debbarma@yahoo.co.in
}

\begin{abstract}
For uninterrupted serviceloperation, a main work force is employed when the workforce is inadequate during peak hours; a reserve of resource pool has to be maintained, to fulfill the necessity. In many cases, the optimal work force in the reserve pool is laborious to determine or may be an approximate figure. To find the optimal manpower/resource pool, a mathematical model using Steady state probability is coined for uninterrupted service. The model may be used for different other requirements like sourcing goods/materials from suppliers, and to determine the optimal capacity of the in-house facility.
\end{abstract}

Keywords: Optimal manpower in Reserve pool, Steady state probability

\section{INTRODUCTION}

To provide an uninterrupted service the main workforce, is employed. When the main workforce is not adequate for absenteeism and such reasons, persons from the reserve pool are utilized. Examples of additional nurses in the hospital, ticket reservation desk - assistants in a reservation system or machine operators in a factory, can be given to illustrate this. In this article, we discuss a model, constructed on some approximating assumptions, to determine an optimal number of persons who are to be put in the reserve, in such situations. It is perhaps worthwhile to note here that, the applicability of statistical techniques for planning of man power, though in somewhat a different context of deciding on the recruitment, training and promotional policies in an organization where employees may move from class to class, has been illustrated by various authors [1].

\section{MODEL AND ANALYSIS}

\subsection{Model}

It is assumed that:

i) There are $n$ machines and one operator operates each machine. These $\mathrm{n}$ operators form the main work force. In addition, there is a reserve pool in which there are $\mathrm{m}$ operators.

ii) In the absence of an operator of the main workforce, an operator from the reserve pool is deputed in his place, provided the reserve pool has adequate persons at that moment to permit this; if this is not possible at that moment, this is done whenever, at earliest as possible. All the machines have the same priority in this respect.

iii) Let $\mathrm{F}$ (.) be the distribution of the random variable which denotes the time after which an operator (in the main work force) takes a break, and $G$ (.) be the distribution of the length of a break. Let $\mu \mathrm{F}$ and $\mu \mathrm{G}$ be the means of $F($.) and $G($.$) respectively (0<\mu F, \mu G<\infty)$

iv) No operator in the reserve pool is absent when there is a need. That is, if it is required, $m$ operators can always be taken from the reserve pool.

v) Cost per unit time for an unmanned machine is $\mathrm{C} 1$ and the cost per unit time for a person in the reserve pool is $\mathrm{C} 2$.

vi) All the random variables are independent.

\subsection{Analysis}

We take the objective function as the long-term average cost per unit time.

Let $\mathrm{N}(\mathrm{t})$ give the number of operators (of the main work force) absent at time $t$ and $S(t)$ the number of unmanned machine at time t. then, if $N(t)=m+j, S(t)=j ; j=0,1 \ldots, n-m$. In an interval $[\mathrm{t}, \mathrm{t}+\Delta \mathrm{t}]$ the cost incurred is C1.S (t) $\Delta \mathrm{t}+\mathrm{C} 2 . \mathrm{m}$. $\Delta \mathrm{t}$, where $\Delta \mathrm{t}$ is sufficiently small. Thus, the long term expected cost per unit time can be written, as a function of $\mathrm{m}$, as, 


$$
\begin{gathered}
C(m)=\lim _{T \rightarrow \infty}\left(\frac{1}{T}\right) E\left(C 1 \int_{0}^{T} S(t) d t+C 2 m \int_{0}^{T} d t\right. \\
=\lim _{T \rightarrow \infty}(C 1 / T) E\left[\int_{0}^{T} S(t) d t\right]+C 2 m
\end{gathered}
$$

Define $X i(t)=1$, if $N(t)=m+I,(i=1,2, \ldots, n-m), X i(t)=0$, otherwise. Then, $\mathrm{S}(\mathrm{t})=\sum \mathrm{i}$. Xi (t). And,

$\lim _{T \rightarrow \infty} \frac{1}{T} E\left[\int_{0}^{T} S(T) d t\right]=\sum_{i=1}^{n-m} L\left[\lim _{T \rightarrow \infty}\left(\frac{1}{T}\right) E \int_{0}^{T} X_{i} l(t) d t=\sum_{i=1}^{n-m} L A_{i}\right.$

Where,

$$
A_{i}=\lim _{t \rightarrow \infty} P\left(X_{i} i(t)=1\right)
$$

If the limits exist (Lemma 2.2, Barlow and Proschan 1975) [2, $4,5]$; next, let $\mathrm{p}(\mathrm{t})$ be the probability that an operator is absent at time $t$, since the operators act independently and identically.

$$
F\left(X_{i}(t)=1\right\}={ }^{n} C_{m+i}[p(t)]^{(m+1)}[1-p(t)]^{n-(m+t)}
$$

By the theorem of steady state probabilities in a two stage, alternating renewal process [3-5]

$$
\bar{p}=\lim _{t \rightarrow \infty} p(t)=\mu_{F} /\left(\mu_{F}+\mu_{G}\right)
$$

Thus,

$$
\lim _{t \rightarrow+\infty} p\left(X_{i} l(t)=1\right)={ }^{n} C_{m+i}[p(t)]^{(m+i)}[1-p(t)]^{n-(m+1)}
$$

Hence,

$$
\begin{aligned}
& \bar{c}(m)=c_{1} \sum_{i=1}^{n-m}{ }^{n} c_{m+1} i \cdot(\bar{p})^{(m+i)}(1-\bar{p})^{n-c m+i)}+c_{2} \cdot m \\
& =c_{1}\left\{\sum_{k=m+1}^{n} k^{n} c_{k}(\bar{p})^{k}(\bar{q})^{n-k}-m \Sigma^{n} c_{k}(\bar{p})^{k}(\bar{q})^{n-k}\right\}+\left(c_{2}\right) m \\
& \ldots \ldots \ldots \ldots \ldots \ldots \text { (e) }
\end{aligned}
$$

Where, $\bar{q}=1-\bar{p}$

It is straightforward to see that,

$$
\bar{c}(m)<(>) \bar{C}\left(m_{1}\right)
$$

If,

$$
\sum_{k=n+1}^{n} k^{n} C_{k}(\bar{p})^{k}(\bar{q})^{n-k}<(p)^{c_{2} / c_{1}}
$$

The LHS of 2.1 is the complement of the binomial distribution with parameters $(\mathrm{n}, \bar{p})$. For $\mathrm{m}=0$, the LHS $=1-q^{-n}$. Thus, if $1-q^{-n}>c_{2} / c_{1},(0<\bar{p}<1)$ then there exist a non zero unique $\left.\widehat{m}_{\text {such that }} \bar{c}_{(} \hat{m}\right) \leq \bar{c}_{(\mathrm{m}), \mathrm{m}=0,1, \ldots, \mathrm{n} \text {, since the LHS is }}$ decreasing with $\mathrm{m}$. the minimizing ${ }^{\hat{m}}$ can be found, in this case, as minimum $\mathrm{m}$ for which LHS $\leq^{\mathrm{c}_{2}} / \mathrm{c}_{1}$, and can be calculated without any great difficulty. The binomial distribution table may be used, and can be approximated by the Poisson's distribution table when $\mathrm{n}$ is large, and for still larger $\mathrm{n}$ the standard normal distribution table can be used. Also, we may note that, the optimal ${ }^{\widehat{m}}$ is a minimize as long as,

$\sum_{d_{k=\hat{m}}}^{n}{ }^{n} C_{k}(\bar{p})^{k}(\bar{q})^{n-k} \leq\left(c_{2} / c_{1}\right)<\sum_{k=\hat{w}-1}^{n}{ }^{n} C_{k}(\bar{p})(\bar{q})^{n-k}$ (g)

\subsection{Numerical Example}

Take ${ }^{\bar{p}}=0.05, \quad c_{2} / c_{1}=0.1$; the following table gives the optimal $^{\widehat{m}}$ for different values of $\mathrm{n}$, and the sensitivity range of $\left(2 / c_{1}\right)$ in which ${ }^{\hat{m}}$ is optimal.

Table 1 Different Values of n, and optimal $\widehat{m}$

\begin{tabular}{|l|l|l|}
\hline $\mathrm{n}$ & $\hat{m}$ & $\left.\mathrm{c}_{2} / \mathrm{c}_{1}\right)$ Sensitivity \\
\hline 5 & $1+1$ & $0.0226-0.2262$ \\
\hline 10 & $1+1$ & $0.0861-0.4013$ \\
\hline 15 & $2+1$ & $0.0362-0.171$ \\
\hline 20 & $2+1$ & $0.0755-0.2642$ \\
\hline 30 & $3+1$ & $0.068-0.191$ \\
\hline 40 & $4+1$ & $0.053-0.143$ \\
\hline
\end{tabular}

\section{CONCLUSIONS}

A model is presented by which the optimal manpower in reserve for an essential service may be determined. Though the assumptions of independence of the random variables, assumption of uniform pay for the persons in the reserve pool, etc. are somewhat restrictive, but overall, it is quite indicative. 
In a numerical example, it is seen that the extra manpower required for a fixed number of machines decreases as the total number of machines increases.

The same model may be valid for the situations, which are similar to that discussed here. For example, when a certain commodity is sourced from different suppliers, who may stop the supply for a temporary period sometimes, and there is an in house sourcing also to make up for this the same analysis may be applicable to determine the optimal capacity of the in house facility.

\section{REFERENCES}

[1] Bartholomew, D. J., and A. F. Forbes 1979, "Statistical techniques for manpower planning", Wiley. Chichester [Eng.]; New York

[2] Barlow, R. E., and Proschan, F. (1975), "Statistical theory of Reliability and life testing: Probability Models", Holt, Rinehart and, Winston, New York.

[3] W. Feller, "An Introduction to Probability Theory and Its Applications," vol. 11, New York: Wiley, 1966.

[4] Kall, P. and J. Mayer 2005. "Stochastic linear programming: models, theory, and computation", Springer Science, New York

[5] J. R. Birge and F. Louveaux, "Introduction to Stochastic Programming", New York: SpringerVerlag, 1997. 